\title{
Assessment of TRACE CCFL Model with SBLOCA Experiment of IIST Facility
}

\author{
Jung-Hua Yang, ${ }^{1}$ Jong-Rong Wang, ${ }^{2}$ Hao-Tzu Lin, ${ }^{2}$ and Chunkuan Shih ${ }^{3}$ \\ ${ }^{1}$ Department of Engineering and System Science, National Tsing Hua University, No. 101, Section 2, Kuang Fu Road, \\ Hsinchu 30013, Taiwan \\ ${ }^{2}$ Institute of Nuclear Energy Research, Atomic Energy Council, R.O.C., No. 1000, Wenhua Road, Jiaan Village, Longtan Township, \\ Taoyuan 32546, Taiwan \\ ${ }^{3}$ Institute of Nuclear Engineering and Science, National Tsing Hua University, No. 101, Section 2, Kuang Fu Road, \\ Hsinchu 30013, Taiwan
}

Correspondence should be addressed to Jung-Hua Yang, junghua1984@gmail.com

Received 15 October 2011; Accepted 26 December 2011

Academic Editor: Thomas Hoehne

Copyright (C) 2012 Jung-Hua Yang et al. This is an open access article distributed under the Creative Commons Attribution License, which permits unrestricted use, distribution, and reproduction in any medium, provided the original work is properly cited.

\begin{abstract}
In this paper, the TRACE model for IIST facility is developed and verified with the Small Break loss of coolant accident (SBLOCA) experiment of IIST (Institute of Nuclear Energy Research Integral System Test) facility. By using the Wallis and Kutateladze correlations of countercurrent flow limitation (CCFL) model, the TRACE analyses results, such as break flow rate, primary pressure, and the temperature of cold-leg and hot-leg, are consistent with the IIST data. The results show the Kutateladze correlation of CCFL model can well predict the SBLOCA behavior and present good agreement with IIST experiment data in this paper. Besides, the sensitivity study results of Kutateladze correlation in CCFL model are verified and compared with the IIST data.
\end{abstract}

\section{Introduction}

A reduced-height and reduced-pressure IIST facility has been established for safety studies of the Westinghouse three loops pressurized water reactor (PWR) since 1992. The research purposes of the IIST facility are enhancement of understanding of thermal hydraulics phenomena during the accidents [1-3], contributing to evaluate and develop the safety computer codes $[4,5]$, and validation of EOP during the accidents of PWR [6]. The IIST facility has three loops as well as all the systems associated with Westinghouse PWR plant system transients. The maximum operating pressure of the IIST facility is $2.1 \mathrm{MPa}$. CCFL is an important phenomenon in a reactor system. In a PWR, countercurrent flow (CCF) may occur in both the hot-leg and the entrance to the steam generator during LOCA. CCF also occurs during blowdown as the Emergency Core Cooling Systems (ECCSs) fill water into the downcomer. When the CCFL occurs, the mass and heat transfer between gas and liquid phases reduces, and a water pool forms. This phenomenon prevents the core from cooling such that the fuel temperature rapidly increases [7]. Therefore, studies on CCF and CCFL are essential for proper nuclear reactor safety.

The codes used in this paper are TRACE $v 5.0 \mathrm{p} 2$ and SNAP v 2.0.3. TRACE (TRAC/RELAP Advanced Computational Engine) is an advanced and best estimate reactor systems code for analyzing thermal hydraulic behaviors in light water reactors [8]. TRACE consolidates the capabilities of the four codes, TRAC-P, TRAC-B, RELAP 5, and RAMONA, into one modernized code. One of the features of TRACE is its capability to model the reactor vessel with 3D geometry. It can support a more accurate and detailed safety analysis of nuclear power plants. TRACE has a greater simulation capability for loss of coolant accident. Furthermore, a graphic user interface program, SNAP (Symbolic Nuclear Analysis Package), which is being under development by Applied Programming Technology, Inc. for conveniently creating and editing the input decks.

According to the best LOCA simulation capability of TRACE, this paper focuses on the development of TRACE 


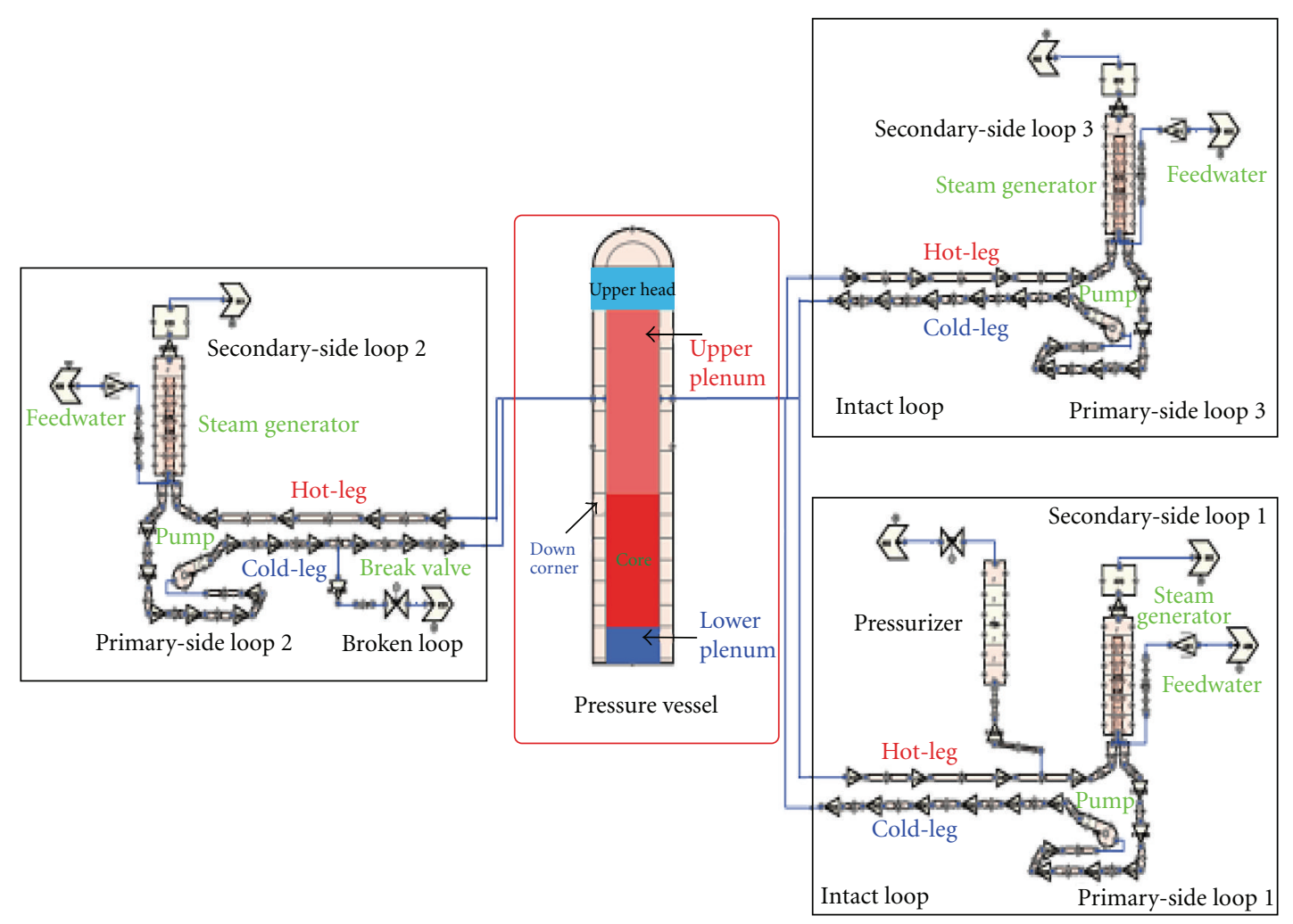

FIgURE 1: The TRACE model for IIST facility.

IIST model and analysis of the SBLOCA with the IIST experiment data. The results of different form of CCFL model, such as Wallis correlation and Kutateladze correlation, are also verified with the IIST data in this study. Furthermore, the sensitivity studies of CCFL model in water level and core cladding temperature are discussed.

\section{IIST Facility and SBLOCA Experiment}

Figure 1 shows the TRACE model of IIST facility. IIST facility is established in order to simulate the thermal hydraulics phenomena of Maanshan NPP, which is a Westinghouse three loops PWR. The IIST facility consists of a pressure vessel and three loops. Each loop has a steam generator (SG) and a coolant pump [9]. Except that there is a pressurizer in the loop 1, the three loops are identical. The scaling factors of height and volume in the RCS are approximately $1 / 4$ and $1 / 400$, respectively. Scaled safety injection systems (include HPI and accumulators) inject cooling water into the cold-leg of each loop. During the SBLOCA experiment [10], a catch tank is simulated to collect and measure the effluent from the simulated break. The comparison of major parameters between IIST facility and the Maanshan NPP is shown in Table 1.

The experiment of IIST facility was performed in order to simulate a $2 \%$ cold-leg break (the break area is $2 \%$ of the scaled cold-leg cross-section area) with total HPI failure [11]. This break is located in loop 2 of IIST facility, which is one of the two loops that do not have a pressurizer. In this experiment, the core power decay and pump coastdown during the SBLOCA experiment were not simulated. The initial condition of the experiment is shown in Table 2.

\section{CCFL Model in TRACE}

CCFL is an important issue related to the safety analysis of PWRs. CCFL phenomenon determines the maximum velocity of one phase relative to the other one when the velocity of neither of the two phases can increase further without flow regime change [12]. CCFL may occur in the downcomer, the upper core tie plate, the hot legs, the entrance of the SG inlet plenum, and the pressurizer surge line, where the flow direction or flow area changes. The TRACE code has the ability to calculate the CCF and predict the CCFL by applying the CCFL model at the flow path. The CCFL correlation can be applied at specific locations in the $3 \mathrm{D}$ component and in the $1 \mathrm{D}$ vertical component. The CCFL correlations can be represented as Wallis form [13], Kutateladze form [14], and Bankoff form [15]. In TRACE, the CCFL model basically uses the Bankoff correlation, because the correlation reverts to the Wallis form by setting the scaling constant $\beta=0$, and reverts to the Kutateladze form by setting $\beta=1$.

Equations (1) and (2) show the Wallis correlation and Kutateladze correlation, respectively,

$$
\begin{aligned}
& J_{g}^{1 / 2}+m_{W} J_{l}^{1 / 2}=C_{W}, \\
& K_{g}^{1 / 2}+m_{K} K_{l}^{1 / 2}=C_{K},
\end{aligned}
$$


TABLE 1: The comparison of major parameters between IIST facility and the Maanshan NPP.

\begin{tabular}{|c|c|c|c|}
\hline Parameter & IIST & Maanshan PWR & IIST/PWR \\
\hline Design pressure $(\mathrm{MPa})$ & 2.1 & 15.6 & $1.35 \times 10^{-1}$ \\
\hline Maximum core power (MW) & 0.45 & 2775 & $1.62 \times 10^{-4}$ \\
\hline Primary system volume $\left(\mathrm{m}^{3}\right)$ & $5.37 \times 10^{-1}$ & $2.15 \times 10^{2}$ & $2.50 \times 10^{-3}$ \\
\hline Number of loops & 3 & 3 & 1 \\
\hline \multicolumn{4}{|l|}{ Core } \\
\hline Height (m) & 1.0 & 3.6 & $2.77 \times 10^{-1}$ \\
\hline Hydraulic diameter (m) & $1.08 \times 10^{-1}$ & $1.22 \times 10^{-2}$ & 8.85 \\
\hline Bypass area $\left(\mathrm{m}^{2}\right)$ & $7.2 \times 10^{-5}$ & $1.54 \times 10^{-2}$ & $4.67 \times 10^{-3}$ \\
\hline \multicolumn{4}{|l|}{ Hot leg } \\
\hline Inner diameter, $D(\mathrm{~m})$ & $5.25 \times 10^{-2}$ & $7.35 \times 10^{-1}$ & $7.13 \times 10^{-2}$ \\
\hline Length, $L(\mathrm{~m})$ & 2.0 & 7.28 & $2.75 \times 10^{-1}$ \\
\hline$L / \sqrt{D}\left(\mathrm{~m}^{0.5}\right)$ & 8.72 & 8.48 & 1.03 \\
\hline \multicolumn{4}{|l|}{ U-tube in one SG } \\
\hline Number & 30 & 5626 & $5.33 \times 10^{-3}$ \\
\hline Average length (m) & 4.08 & 16.85 & $2.24 \times 10^{-1}$ \\
\hline Inner diameter $(\mathrm{mm})$ & 15.4 & 15.4 & 1.0 \\
\hline Volume $\left(\mathrm{m}^{3}\right)$ & $2.28 \times 10^{-2}$ & 18.44 & $1.23 \times 10^{-3}$ \\
\hline \multicolumn{4}{|l|}{ Cold leg } \\
\hline Inner diameter, $D(\mathrm{~m})$ & $5.25 \times 10^{-2}$ & $7.87 \times 10^{-1}$ & $6.67 \times 10^{-2}$ \\
\hline Length, $L(\mathrm{~m})$ & 5.0 & 15.7 & $3.18 \times 10^{-1}$ \\
\hline$L / \sqrt{D}\left(\mathrm{~m}^{0.5}\right)$ & 21.8 & 17.69 & 1.22 \\
\hline \multicolumn{4}{|l|}{ Downcomer } \\
\hline Flow area $\left(\mathrm{m}^{2}\right)$ & 0.0185 & 2.63 & $7.03 \times 10^{-2}$ \\
\hline Hydraulic diameter (m) & $4.12 \times 10^{-2}$ & $4.8 \times 10^{-1}$ & $8.58 \times 10^{-2}$ \\
\hline \multicolumn{4}{|l|}{ Pressurizer } \\
\hline Volume $\left(\mathrm{m}^{3}\right)$ & $9.32 \times 10^{-2}$ & 39.64 & $2.35 \times 10^{-3}$ \\
\hline Surge-line flow area $\left(\mathrm{m}^{2}\right)$ & $3.44 \times 10^{-4}$ & $6.38 \times 10^{-2}$ & $5.39 \times 10^{-3}$ \\
\hline
\end{tabular}

where $J_{k}$ and $K_{k}$ are dimensionless mass flux ( $k$ : gas or liquid). The $m$ and $C$ are constants determined from the experiments

$$
\begin{aligned}
& J_{k}=j_{k}\left[\frac{\rho_{k}}{g d\left(\rho_{f}-\rho_{g}\right)}\right]^{1 / 2}, \\
& K_{k}=j_{k}\left[\frac{\rho_{k}^{2}}{g \sigma\left(\rho_{f}-\rho_{g}\right)}\right]^{1 / 4} .
\end{aligned}
$$

Here, $j_{k}$ and $\rho_{k}$ are the superficial velocity and the density of phase ( $k$ : gas or liquid), $d$ is the hole diameter, and $\sigma$ is the surface tension.

\section{Results and Discussions}

4.1. Analysis Results of CCFL Model. In this study, the CCF may occur in the hot leg, the entrance to the steam generator, and the pressurizer surge line in IIST SBLOCA experiment. In order to verify the SBLOCA prediction of TRACE CCFL model, the comparisons of the results among Wallis correlation, Kutateladze correlation, and IIST data are considered in this paper. From (3), the hydraulic diameters
TABLE 2: The initial condition of the IIST SBLOCA experiment.

\begin{tabular}{lc}
\hline \multicolumn{1}{c}{ Parameter } & IIST test data \\
\hline \multicolumn{2}{c}{ Primary coolant system } \\
\hline Core power $(\mathrm{kW})$ & 126 \\
Pressurizer pressure $(\mathrm{MPa})$ & 0.958 \\
Pressurizer water level $(\mathrm{m})$ & 1.459 \\
Loop flow rate $(\mathrm{kg} / \mathrm{s})$ & 0.217 \\
Hot-leg temperature $(\mathrm{K})$ & 450 \\
Cold-leg temperature $(\mathrm{K})$ & 409 \\
\hline \multicolumn{2}{c}{ Secondary coolant system } \\
\hline Secondary-side pressure (MPa) & 0.295 \\
Secondary-side fluid temperature $(\mathrm{K})$ & 407 \\
\hline
\end{tabular}

of pipe from 2.5 to $200 \mathrm{~mm}$ are calculated for the Wallis correlation and Kutateladze correlation of CCFL model, as shown in Figures 2 and 3. The pipe hydraulic diameter of reactor coolant system is $52.5 \mathrm{~mm}$ in IIST facility, so it is chosen the $50 \mathrm{~mm}$ results for the IIST CCFL model analysis in this study. Figure 2 shows the Wallis correlation plotted against the data. The constant $m_{w}$ and $C_{w}$ are both set to 1 from the results of Figure 2. The Kutateladze correlation 


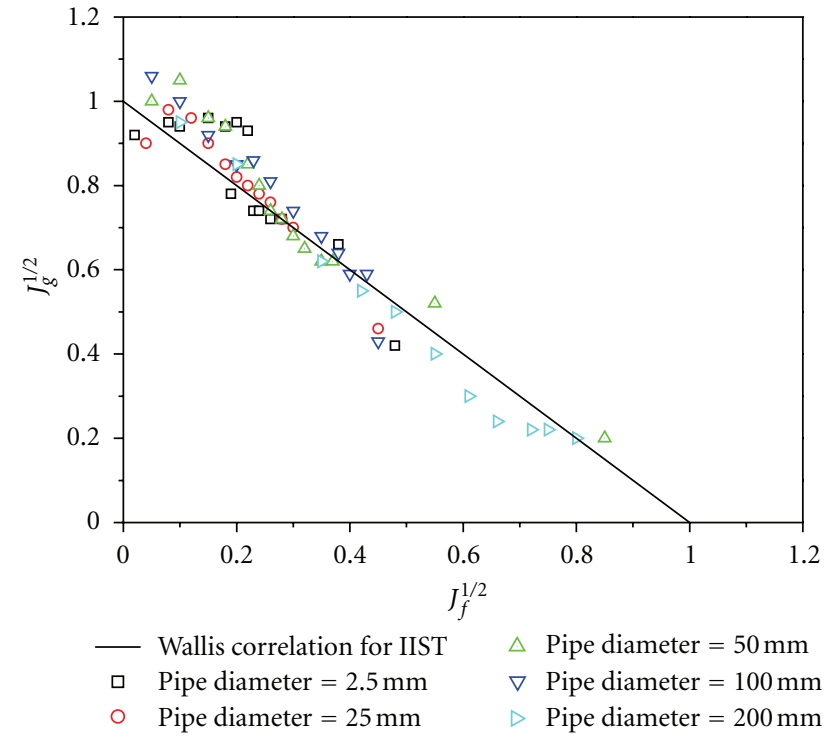

Figure 2: The Wallis correlation comparison with data (pipe diameter $=2.5-200 \mathrm{~mm}$ ).

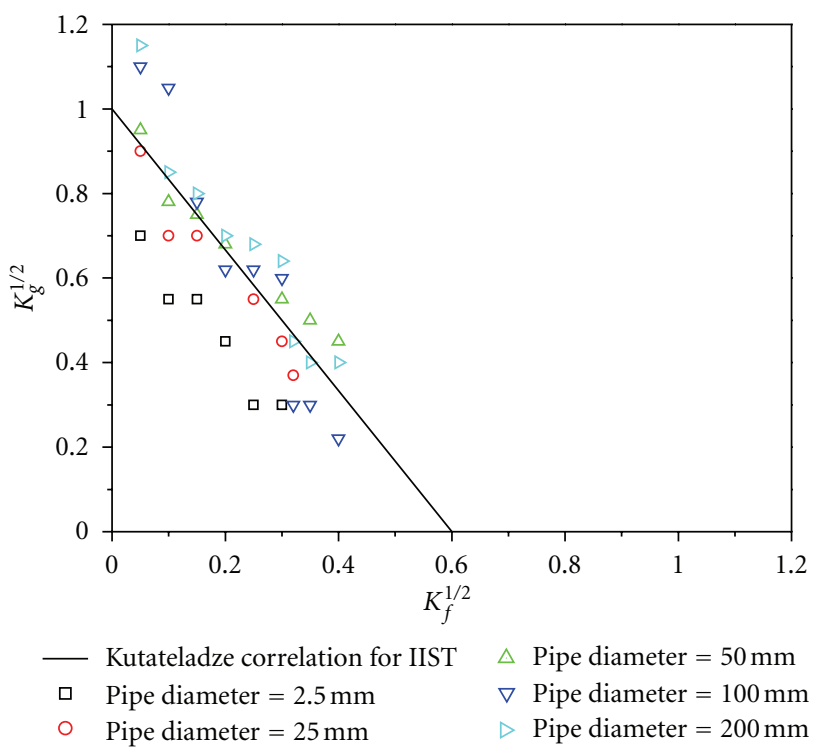

Figure 3: The Kutateladze correlation comparison with data (pipe diameter $=2.5-200 \mathrm{~mm}$ ).

plotted against the data is shown in Figure 3. The constant $m_{k}$ and $C_{k}$ are set to 0.6 and 1 , respectively.

Figure 4 shows the comparison of break flow rate and primary system pressure among Wallis form, Kutateladze form, and IIST data. The break flow rate and primary system pressure trends of Wallis form, and Kutateladze form are similar with the IIST data. Asymmetric natural-circulation flow rates were observed in the three loops during the IIST SBLOCA experiment. Figure 5 shows the comparison of loop 1 and loop 3 flow rate among Wallis form, Kutateladze form, and IIST data in the SBLOCA experiment. The trends of Wallis form and Kutateladze form are similar to the IIST

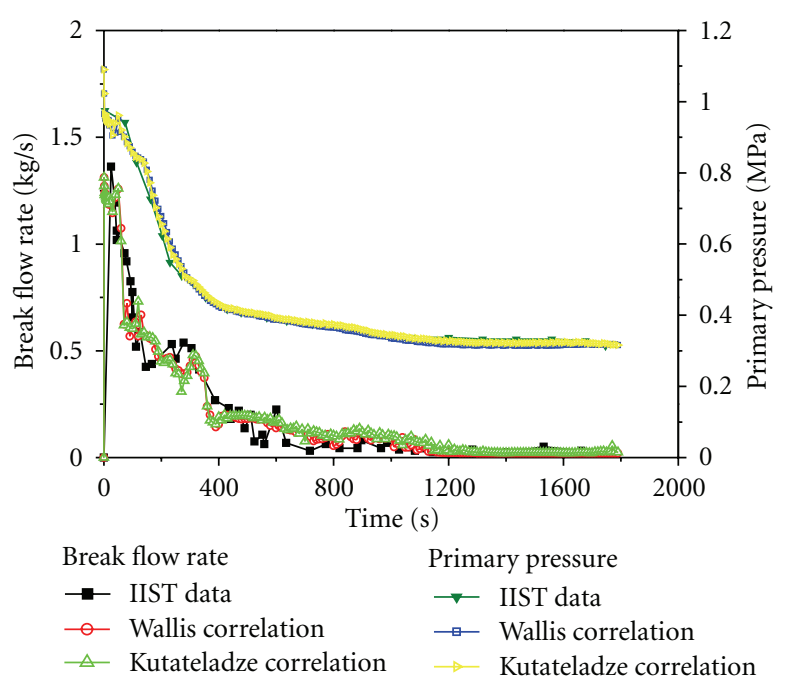

Figure 4: The comparison of break flow rate and primary pressure among Wallis form, Kutateladze form, and IIST data.

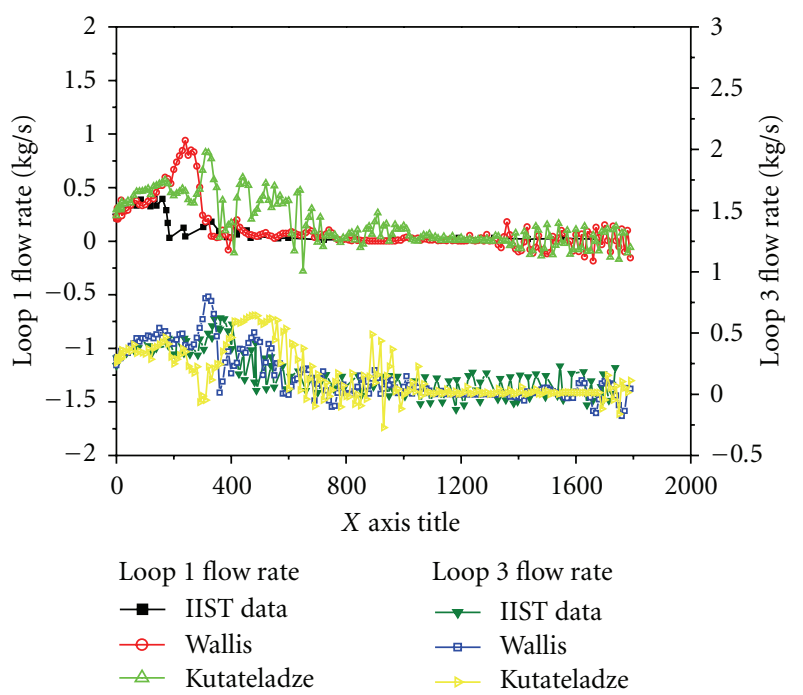

FIGURE 5: The comparison of loop 1 and loop 3 flow rate among Wallis form, Kutateladze form, and IIST data.

data. For loop 1, the IIST data show the inlet and outlet plenum of SG1 to empty after $500 \mathrm{~s}$, as shown in Figure 6. Figure 6 indicates the Wallis form of CCFL model results compared with the IIST data are overpredicted during 400 1600 s. The Kutateladze form predictions of water level in the SG1 inlet plenum are the same trends with IIST data, except at 100 700 s. Figure 6 also shows the Wallis form and Kutateladze form overpredicted water level in the SG1 outlet plenum at 300 800 s. Figure 7 shows the comparison of the liquid holdup in the SG2 inlet plenum and SG3 outlet among Wallis form, Kutateladze form, and IIST data. There are the similar trends in this parameter. However, the water level of Wallis form and Kutateladze form predicted are lower than IIST data after $300 \mathrm{sec}$. According to the results of SG3 outlet plenum liquid level predicted by Wallis form and Kutateladze 

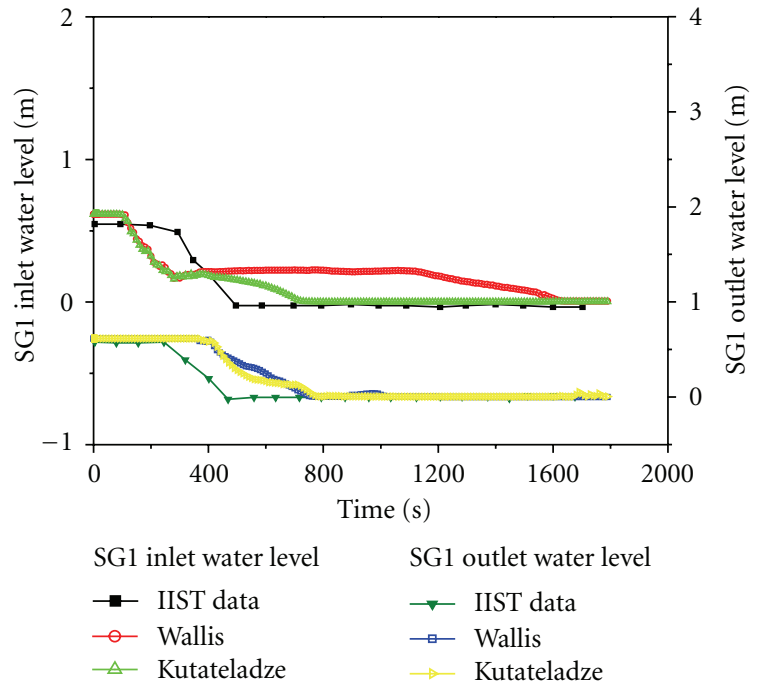

FIGURE 6: The comparison of SG1 inlet and outlet water level among Wallis form, Kutateladze form, and IIST data.

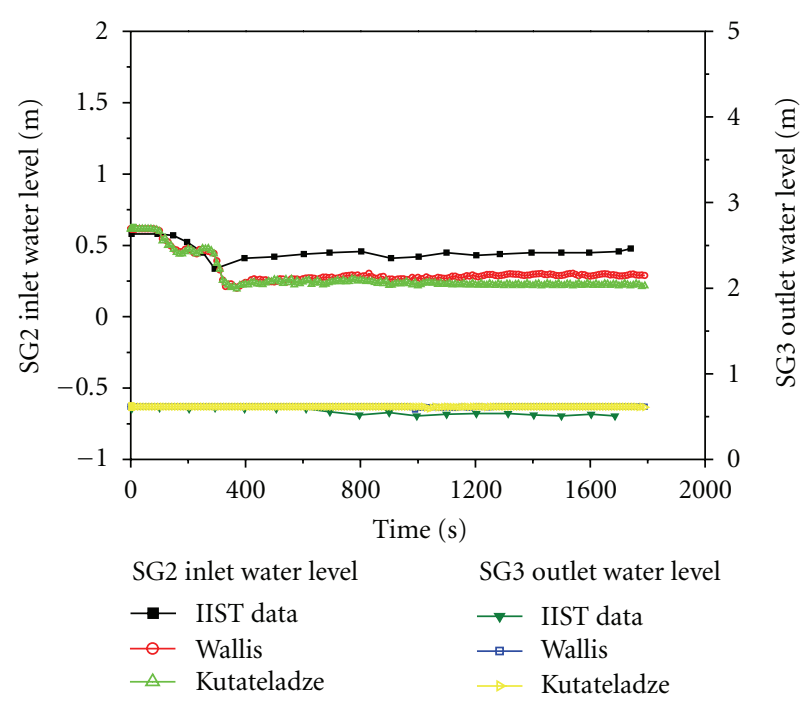

FIGURE 7: The comparison of SG2 inlet and SG3 outlet water level among Wallis form, Kutateladze form, and IIST data.

form, the trends compared with IIST data are generally consistent in $0 \sim 700 \mathrm{~s}$ and overpredicted after $700 \mathrm{~s}$. Figure 8 shows the fluid temperatures of the cold-leg and hot-leg in loop 3. The TRACE predicted the loop 3 fluid temperature to be in good agreement with the IIST experiment data. Figure 9 shows the comparison of the core liquid level and cladding temperature among Wallis form, Kutateladze form, and IIST data. The trends of their curves are similar. Besides, the TRACE can predict the time to reach the core uncover, which caused the core cladding temperature increase, as shown in Figure 9. The results show that the core cladding temperatures of Kutateladze form predicted are the same trends with IIST data. The core cladding temperature begins to increase when the core uncovered. Comparing to IIST

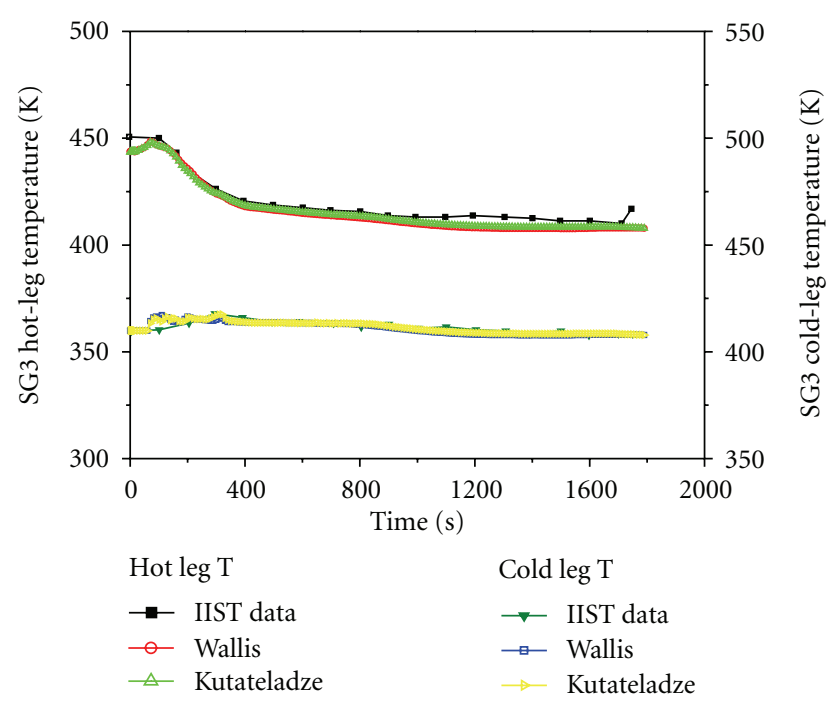

FIGURE 8: The comparison of SG3 hot leg and cold leg temperature among Wallis form, Kutateladze form, and IIST data.

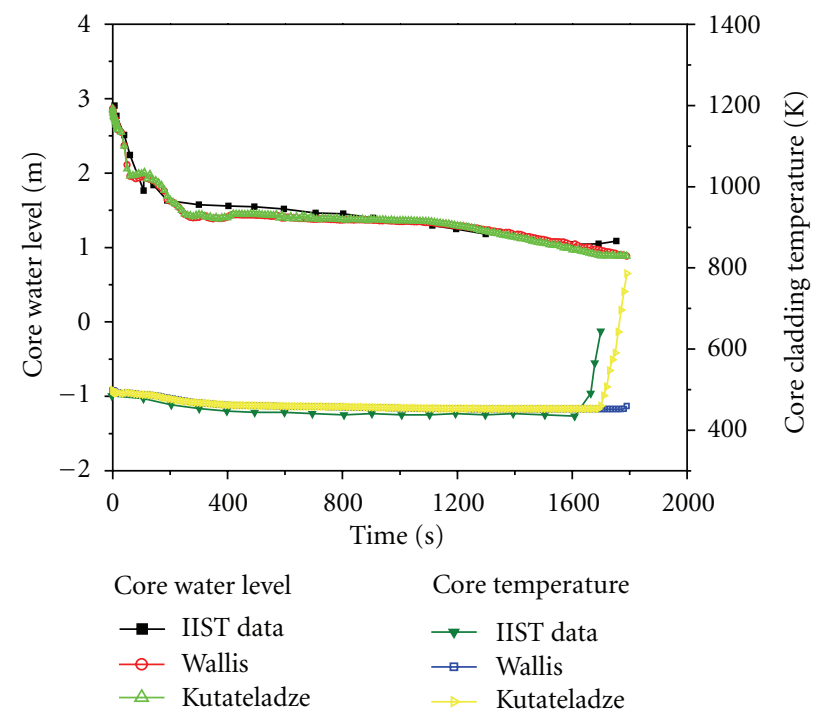

FIGURE 9: The comparison of core water level and cladding temperature among Wallis form, Kutateladze form, and IIST data.

data and Kutateladze form, the trends of core cladding temperature predicted by Wallis correlation do not increase.

4.2. Sensitivity Studies of Kutateladze Correlation. From the results of Section 4.1, it is indicated using Kutateladze form of CCFL model in the IIST that TRACE model has a good SBLOCA behaviors prediction capability. Furthermore, the sensitivity studies of Kutateladze correlation for the water levels and core cladding temperature are verified and discussed in this paper. According to the results of Figure 3, the base values of $C_{k}$ and $m_{k}$ are 1 and 0.6, respectively. The sensitivity studies for Kutateladze correlation are setting the difference value for $m_{k}$ and $C_{k}$. The first method is to maintain the constant $C_{k}$, and set the value of $m_{k}$ for 1.0, 


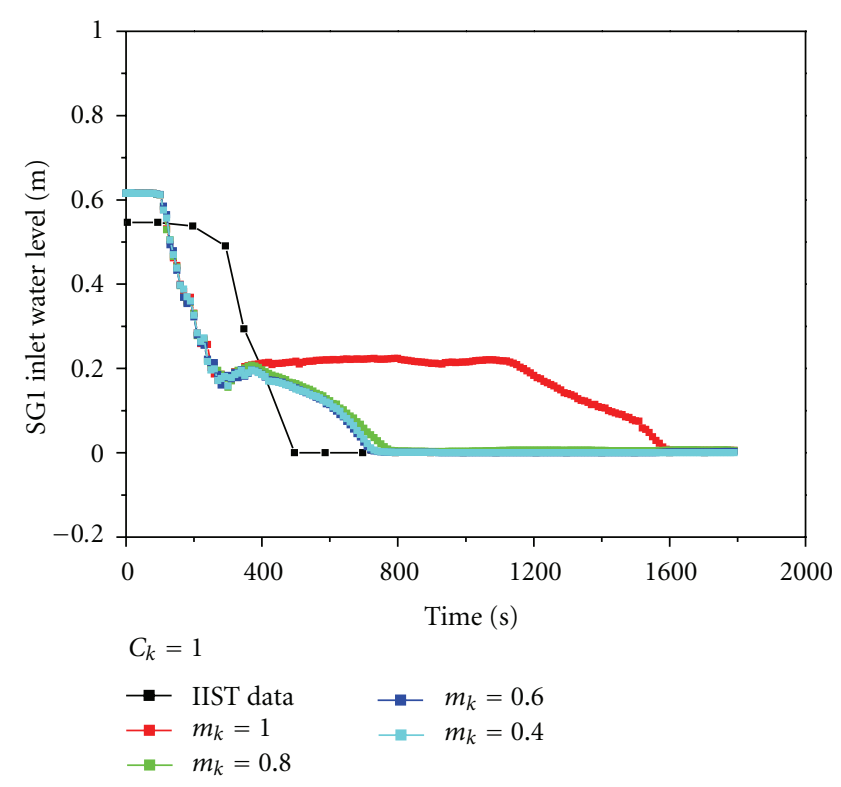

FIGURE 10: The CCFL sensitivity study of $m_{k}$ for SG1 inlet water level.

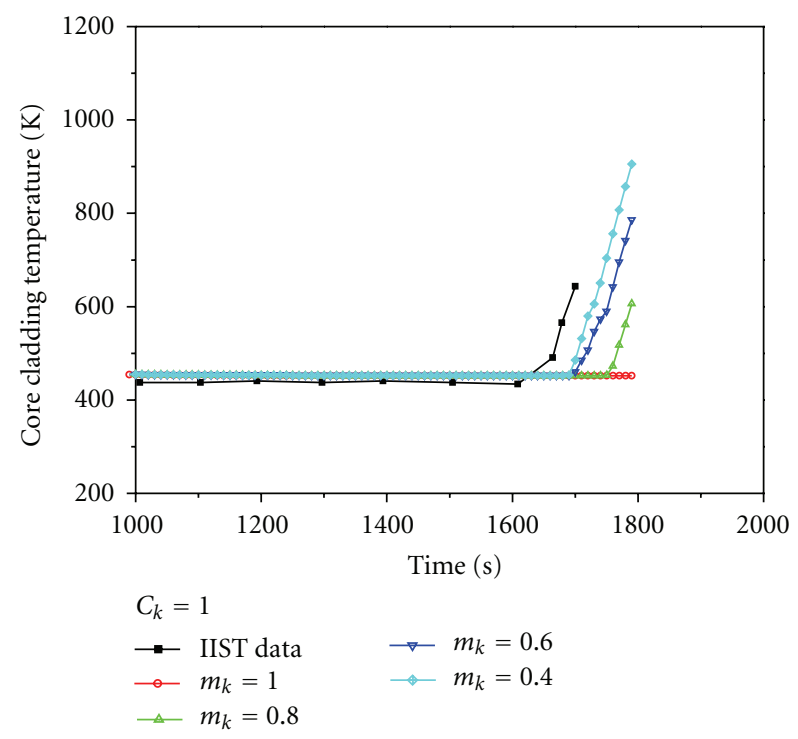

FIgURE 11: The CCFL sensitivity study of $m_{k}$ for core cladding temperature.

$0.8,0.6$, and 0.4 , respectively. The other one is to maintain the constant $m_{k}$ and set the value of $C_{k}$ for $1.2,1.0,0.8$, and 0.6 , respectively. Figure 10 shows the sensitivity study of $m_{k}$ for SG1 inlet water level. The results of $m_{k}=1.0$ case overpredicted the water level after $400 \mathrm{~s}$. By the way, the trends are almost the same without CCFL model. The results of $m_{k}=0.8$ are different from the $m_{k}=0.6$ and $m_{k}=0.4$ between $600 \sim 800 \mathrm{~s}$. It also indicates that the results of $m_{k}=0.6$ and $m_{k}=0.4$ are consistence. Figure 11 shows the sensitivity study of $m_{k}$ for core cladding temperature.

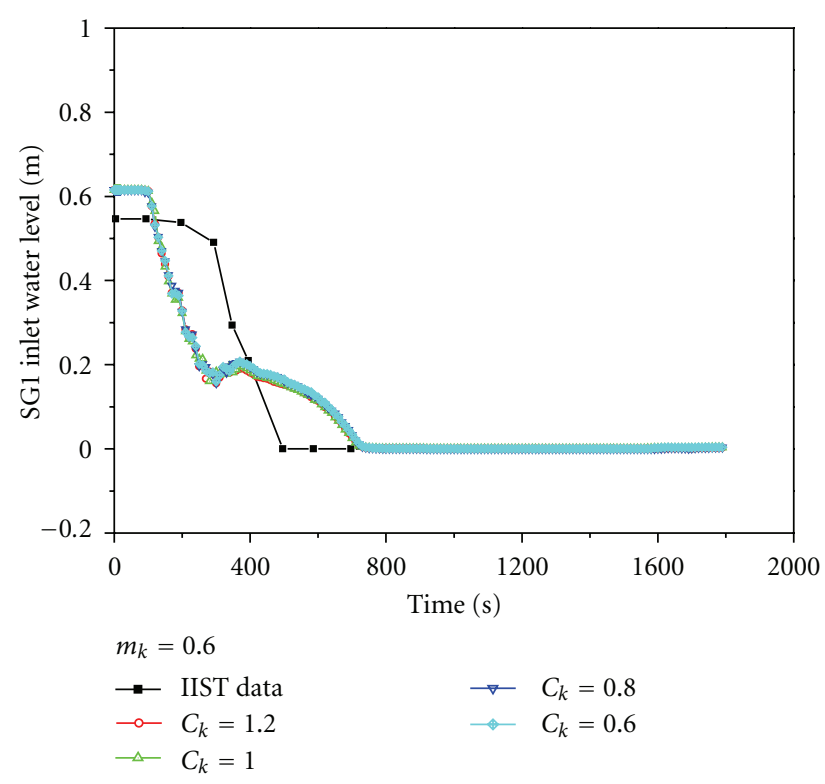

FIGURE 12: The CCFL sensitivity study of $C_{k}$ for SG1 inlet water level.

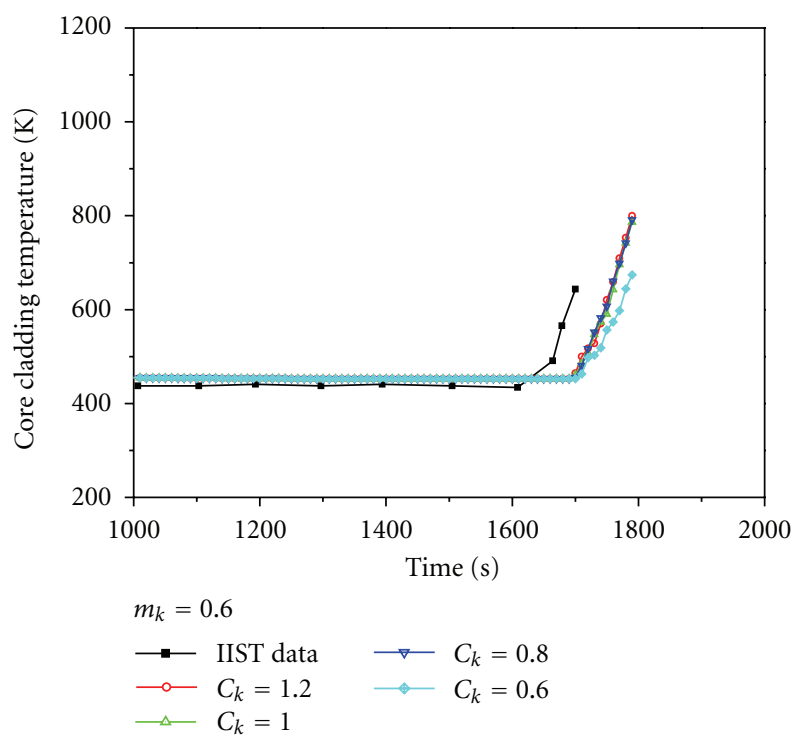

Figure 13: The CCFL sensitivity study of $C_{k}$ for core cladding temperature.

The results of $m_{k}=0.6$ and $m_{k}=0.4$ show to predict the same times to reach the core uncover and to increase the core cladding temperature. The time of $m_{k}=0.8$ predicted is later than $m_{k}=0.6$ and $m_{k}=0.4$. The core cladding temperature curve of $m_{k}=1.0$ does not increase. Figure 12 shows the sensitivity study of $C_{k}$ for SG1 inlet water level. The results of $C_{k}=0.6 \sim 1.2$ are almost the same. It indicates that the different values of $C_{k}$ follow the same trend. The results are also shown in Figure 13. The different values of $C_{k}$ predict 


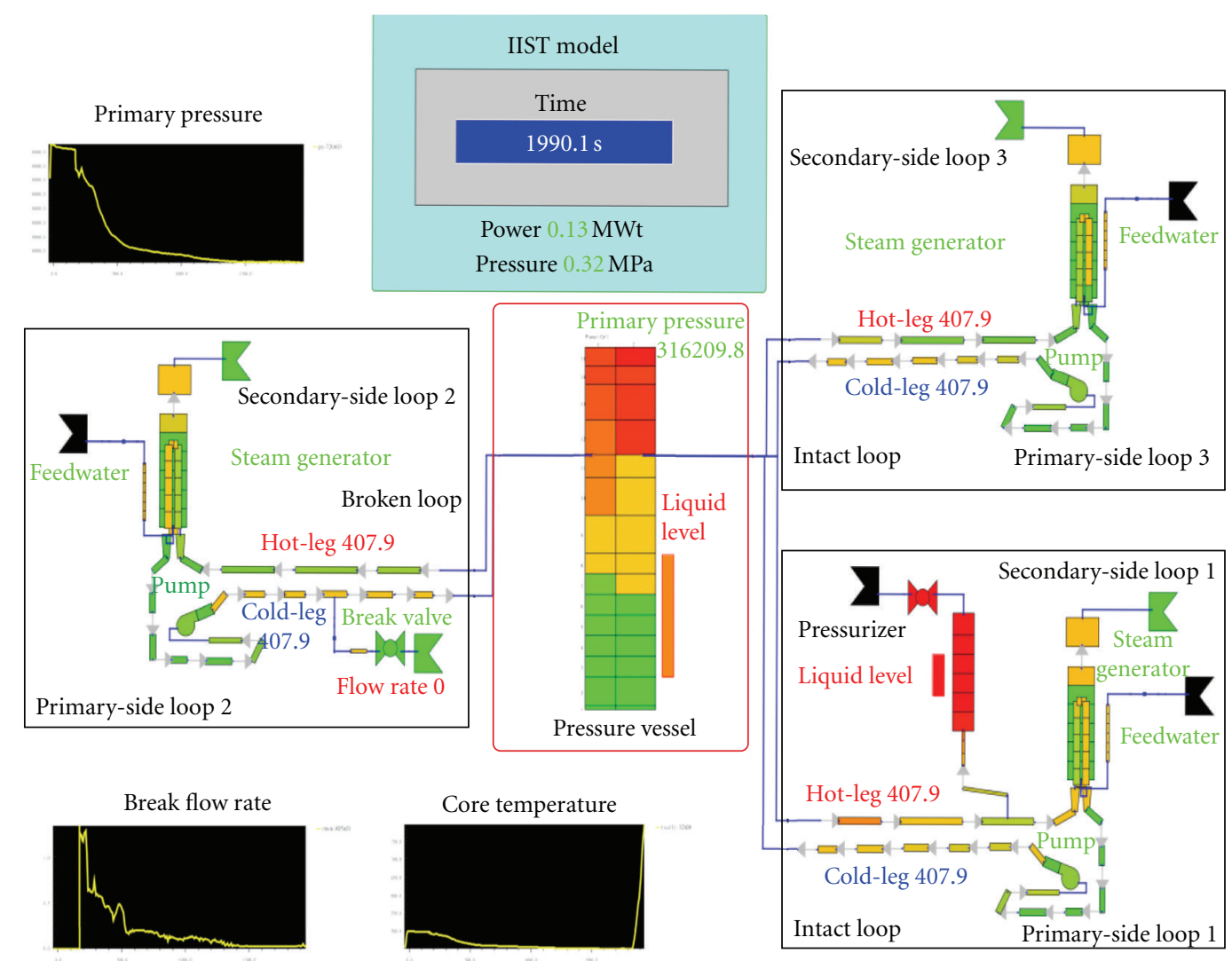

FIgURE 14: Animation of the IIST facility TRACE model for SBLOCA analysis.

the same times to reach the core uncover, and to increase the core cladding temperature.

For the $50 \mathrm{~mm}$ pipe of the reactor coolant system analysis, the above sensitivity studies of CCFL in IIST TRACE model indicate that using the values of $m_{k}=0.6$ and $C_{k}=1$ for Kutateladze correlation can well predict the SBLOCA behavior and the results present good agreement with IIST SBLOCA experiment data.

Furthermore, the animation of the IIST TRACE model is presented using the animation function of TRACE/SNAP interface with analysis results, such as primary pressure, break flow rate, and core cladding temperature. The animation model of IIST is shown in Figure 14.

\section{Conclusions}

By TRACE/SNAP code, the TRACE model for IIST facility is developed and verified with the SBLOCA experiment of IIST facility. In TRACE code, the CCFL model includes the Wallis correlation and Kutateladze correlation. In order to verify the SBLOCA prediction of TRACE CCFL model, the comparisons of the results among Wallis correlation, Kutateladze correlation, and IIST data are considered in this paper. The TRACE analyses results, such as break flow rate, primary pressure, the temperature of cold leg and hot leg, and core cladding temperature, are consistent with the IIST data. It also indicates that the results of Kutateladze form predicted can best represent the results of IIST data. Besides, the sensitivity studies of Kutateladze correlation are verified and discussed in this paper. The best values of $m_{k}$ and $C_{k}$ for IIST TRACE model are 0.6 and 1, respectively. In summary, since our current paper has shown good agreements between IIST data and TRACE results using Kutateladze correlation of CCFL model, future applications of this model are highly recommended for SBLOCA analysis.

\section{References}

[1] C. H. Lee, "INER integral system test (IIST) facility for simulating the Maanshan nuclear power plant-investigation of PWR natural circulation," Journal of Nuclear Science and Technology, vol. 31, p. 83, 1994.

[2] C. H. Lee, T. J. Liu, W. T. Hong, I. M. Huang, Y. K. Chan, and C. J. Chang, "Experimental investigation of PWR small break loss-of-coolant accidents in IIST facility," Journal of Nuclear Science and Technology, vol. 33, pp. 251-259, 1996.

[3] C. H. Lee, T. J. Liu, Y. S. Way, and D. Y. Hsia, "Investigation of mid-loop operation with loss of RHR at INER integral system test (IIST) facility," Nuclear Engineering and Design, vol. 163, no. 3, pp. 349-358, 1996.

[4] Y. M. Ferng and C. H. Lee, "Numerical simulation of natural circulation experiments conducted at the IIST facility," Nuclear Engineering and Design, vol. 148, no. 1, pp. 119-128, 1994.

[5] Y. M. Ferng and C. H. Lee, "Comparison of the RELAP5/ MOD3 code with the IIST natural circulation experiments," Nuclear Technology, vol. 111, no. 1, pp. 34-45, 1995. 
[6] C. Y. Chang, C. H. Lee, T. J. Liu, and Y. K. Chan, "Experimental investigation of loss of feedwater with bleed and feed operation," Journal of Nuclear Science and Technology, vol. 33, pp. 318-323, 1996.

[7] P. S. Damerell and J. W. Simons, "Reactor Safety Issues Resolved by the 2D/3D Program,” NUREG/IA-0127, 1993.

[8] US Nuclear Regulatory Commission (USNRC), TRACE V5.0 User Manual, 2007.

[9] J. R. Wang, H.-T. Lin, C.-J. Chang et al., "The development and verification of TRACE model for IIST experiments," NUREG/IA-0252, 2011.

[10] C. J. Chang, C. H. Lee, W. T. Hong, and L. L. C. Wang, "IIST small break LOCA experiments with passive core cooling injection," Nuclear Engineering and Design, vol. 236, no. 1, pp. 19-34, 2006.

[11] C. H. Lee, I. M. Huang, C. J. Chang, T. J. Liu, and Y. M. Ferng, "Using an IIST SBLOCA experiment to assess RELAP5/MOD3.2," Nuclear Technology, vol. 126, no. 1, pp. 48-61, 1999.

[12] S. Wongwises, "Two-phase countercurrent flow in a model of a pressurized water reactor hot leg," Nuclear Engineering and Design, vol. 166, no. 2, pp. 121-133, 1996.

[13] G. B. Wallis, One Dimensional Two Phase Flow, McGraw-Hill, New York, NY, USA, 1969.

[14] S. S. Kutateladze, "A hydrodynamic theory of changes in the boiling process under free convection conditions," Izvestiya Akademii Nauk SSSR, Otdelenie Tekhnicheskikh Nauk, vol. 8, p. 529, 1951.

[15] S. G. Bankoff, R. S. Tankin, M. C. Yuen, and C. L. Hsieh, "Countercurrent flow of air/water and steam/water through a horizontal perforated plate," International Journal of Heat and Mass Transfer, vol. 24, no. 8, pp. 1381-1395, 1981. 

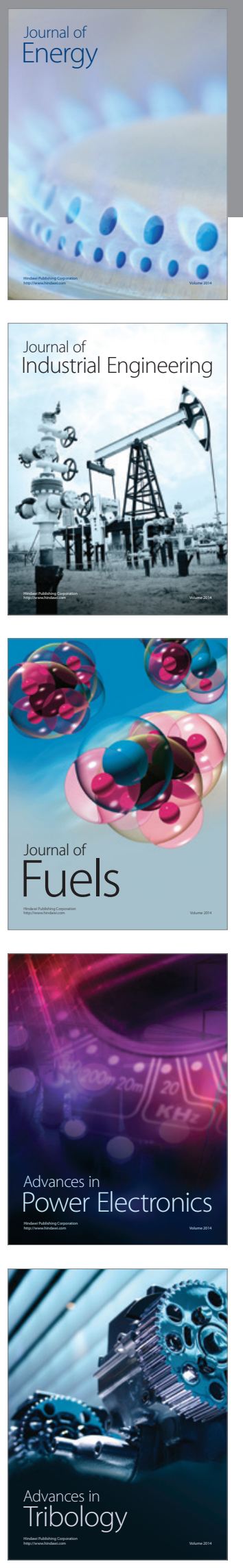
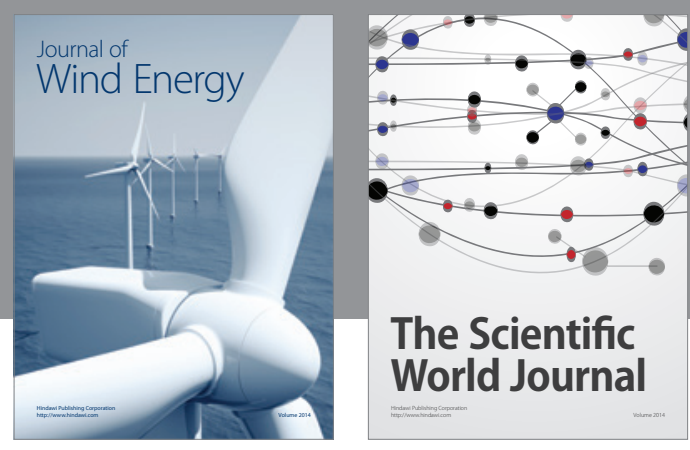

The Scientific World Journal

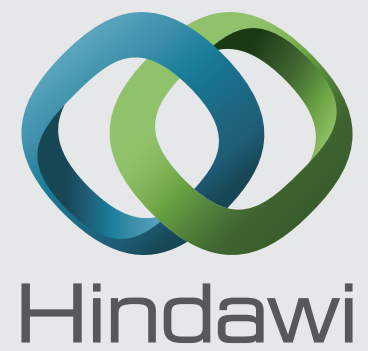

Submit your manuscripts at http://www.hindawi.com
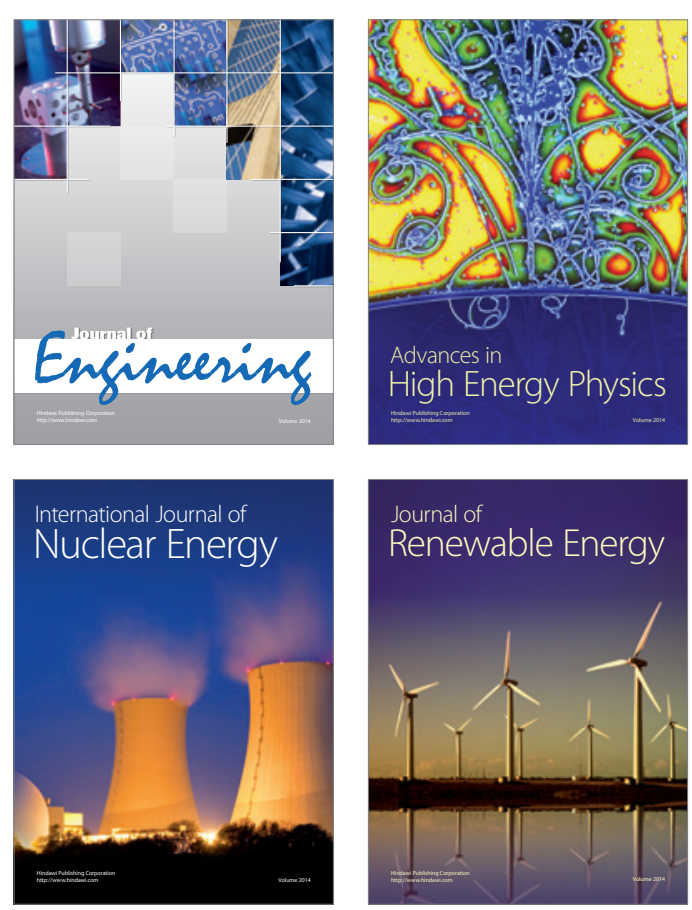

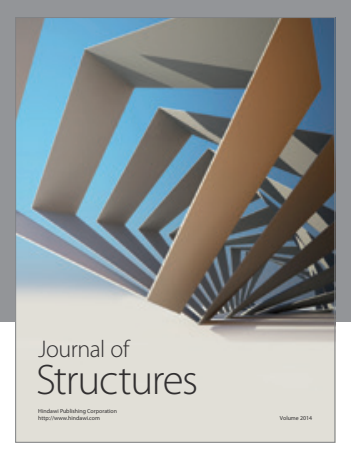

Rotating
Mechinery
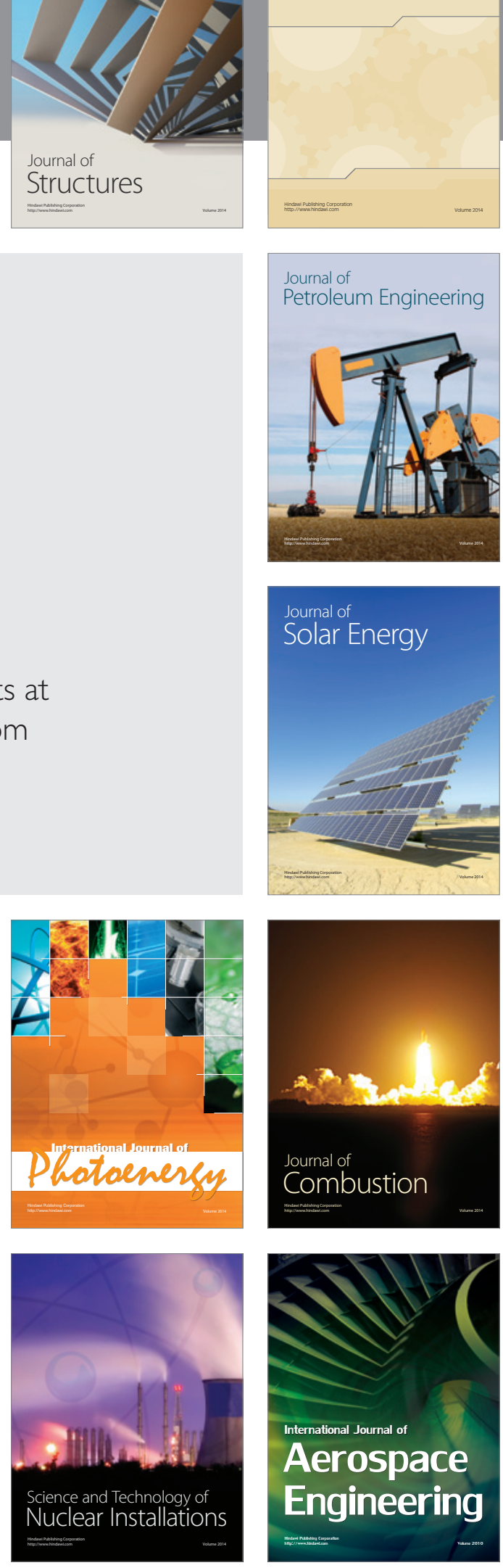